\title{
A More Effective Method to Prevent or Control Diabetes and Alzheimer's Disease
}

\author{
Knox Van Dyke* \\ Professor-Biochemistry, West Virginia University Medical School, USA
}

Submission: March 28, 2017; Published: May 05, 2017

*Corresponding author: Knox Van Dyke, Professor-Biochemistry, West Virginia University Medical School, USA, Email: kvandyke@hsc.wvu.edu

Abbreviations: NO: Nitric Oxide; PN: Peroxynitrite; HAT: Histone Acetyl Transferase; STZ: Streptozotocin; AD: Alzheimer's Disease; PET: Proton Emission Tomography

\section{Introduction}

The human body has only a limited toolbox to prevent and control acute and chronic diseases. A important cell type involved in our immune protection is the monocyte/macrophage which possesses a major inducible chemistry linked to the excessive possible production of gaseous free radical nitric oxide (.NO) produced via nitric oxide synthase 2 (inducible NOS2). In addition, these activated cells can produce considerable amounts of the gas superoxide which is oxygen with an unpaired electron $\left(. \mathrm{O}_{2}^{-}\right)$. When these two free radical substances react together, they produce a peroxide known as peroxynitrite (OON=O-) or [PN]. Under acute conditions- smaller amounts of PN are produced and under chronic inflammatory condition extensive amounts are produced.

Peroxynitrite can react with available carbon dioxide to produce a carbon dioxide -peroxynitrite derivative, a more efficient nitrator. These molecules are used extensively to fight infectious and non-infectious diseases. PN can oxidize and cause nitration, nitrosylation and nitrosation of key biomolecules which are important for life itself e.g. DNA, RNA, proteins and enzymes as well as key protein hormones and important lipids. PN causes damage to viruses, bacteria, fungus, and parasites to prevent overwhelming infections.

The same chemistry is used causing acute and chronic inflammation via inflammatory cells. When acute inflammation occurs, via infection or physical damage, the macrophages are activated to resolve the situation. Unfortunately, if the acute state is not resolved, the disease is converted into a chronic almost unstoppable state. Acute inflammation occurs when round inflammasome- structures made of histone proteins become modified via the addition of two carbon acetate groups caused by histone acetyl transferase (HAT) [1]. This addition of acetate groups covering a positive charged histone causes a neutralization of this positive charge which changes its attraction to negatively charged DNA which allows DNA to become uncovered which stimulates replication of the inflammatory genes and its gene products. As time goes by, there can be a 10 fold increase in peroxynitrite occurring in 24 hours [2] which can be completely abolished if an anti-inflammatory steroid is used in the early part of the inflammatory induction process.

For example, when silica is placed in the lung of a rat- in 24 hours 10 times the peroxynitrite level is produced compared to an animal without silica. If the inflammatory material remains for 6 weeks a plethora of macrophages invade the area and they produce a thousand fold increased amount of peroxynitrite [3]. This causes massive scarring and pathology of the lung with loss of breathing function. The scarring of the alveoli prevents the exchange of oxygen from the capillaries of the lung into the blood.

Further, there is no effective treatment for scarred and permanently damaged lungs. Steroids which cause the deacetylation of histones are totally without effect because excessive peroxynitrite damages the ability of histone deacetylase (HDAC2) to remove the histone's acetate groups. This occurs because there are tyrosines in the active sites of the histone deacetylase which becomes nitrated via peroxynitrite. Once nitrated the HDAC-2 becomes dysfunctional [4].

When insulin was discovered by Banting for treatment of type 1 diabetes, he mentioned in his Nobel address that "insulin was not a cure for diabetes" [5]. He knew that insulin helped control blood sugar but that another process actually controlled the 
disease. This means that even if blood sugar is tightly controlled using insulin or other drugs, the damaging effect of diabetes will continue. We demonstrated this concept in studying early type 1 diabetes in children compared to controls. Regardless of excellent or poor control of blood glucose the blood urate values diminished the same $25 \%$ over a three year period [6].

This means that an additional component was responsible for the loss of urate, and it was likely peroxynitrite which is known to destroy urate. When streptozotocin (STZ) was being developed as an antibiotic around 1960, it was noticed that it caused diabetes when it was injected into rodents. It was said that STZ was toxic to the beta cells of the pancreas and therefore insulin could not be produced or released into the blood and therefore diabetes occurred. We have now demonstrated that STZ generates peroxynitrite and this is the likely cause of diabetes 1 and 2 [7].

Years ago I suggested that peroxynitrite could cause Alzheimer's disease (AD) in Medical Hypothesis originally written in 2004 [8]. Later, it was shown that people who died from Alzheimer's disease had massive nitration in brain proteins in areas where Alzheimer's disease is demonstrated [9]. Recently there have been about 60 publications which suggest that if STZ is injected intra-articularly into normal mouse brain-it produces type 2 diabetes and insulin resistance in their brains in a few days $[10,11]$. In a few months, the mice develop plaques and tangles in Alzheimer's areas. Using a variety of mental and physical tests these same mice demonstrate a dementia like disease which resembles human Alzheimer's disease.

Recently, Alzheimer's disease is being called diabetes 3 in several publications [12]. In 2004, in a publication studying many Alzheimer' patients [13], it was shown that $81 \%$ of these patients had type 2 diabetes or insulin resistance. Does this mean that all Alzheimer's patients had diabetes? No, we know that Alzheimer's can occur from physical damage to the brain (football, hockey, and boxing) and very likely virus infection in the brain can cause AD. Likely, any mechanism that causes chronic inflammation of the brain or spinal cord could cause AD.

Therefore, damage from physical abuse to the brain and various infections or inflammatory diseases can likely trigger acute inflammation with activated macrophages or microglia in the brain. If not treated early and continuously, the damage can develop into chronic inflammation untreatable with steroidal anti-inflammatory drugs. It is apparent that early treatment with drugs which treat type 2 diabetes might be at least partially effective in AD treatment. What is really needed is to control the action of peroxynitrite with drugs or supplements that act like targets of nitration and antioxidants in a continuous manner. We could prevent and treat these diseases, if we interdicted early and continuously. Early dementia can be detected using 18 Fluorodeoxyglucose infusion and proton emission tomography (PET) scan of the brain $[14,15]$.

\section{References}

1. Barnes, Peter J (2006) How corticosteroids control inflammation: Quintiles Prize Lecture 2005. Brit J Pharmacology 148(3): 245-254.

2. VVan Dyke,K., Antonini, J. Wu,L., Ye,Z., and Reasor M (1994) The inhibition of silica-induced lung inflammation by dexamethasone as measured by bronchoalveolar lavage fluid parameters and peroxynitrite-dependent chemiluminescence. Agents and Actions 41(1): 44-49.

3. Castranova, V., Porter,D., Millechia ,L., Ma, and J., andHubbs, A (2002) Effect of inhaled crystalline silica in a rat model: Time course of pulmonary reactions. Mol and Cell Biochry 37: 177-184.

4. Barnes PJ (2000) Chronic obstructive pulmonary disease. N Eng J Med 343(4): 269-280.

5. Banting TG (1923) Nobel prize 1923 shared with McLeod. Nobelprize. org, Sweden.

6. Van Dyke, K (2010) Oxidative/Nitrosative Stresses Trigger Type I Diabetes: Preventable in Streptozotocin Rats and Detectable in Human Disease. Ann NY Acad Sci 1203: 138-145.

7. Andersson DA, Milos RF, Clive G, Mirjam E, Nisha V, et al. (2015) Streptozotocin stimulates the ion channel trpa1 directly involvement of peroxynitrite. J Biol Chem 290: 15185-15196.

8. Van Dyke K (1997) The possible role of peroxynitrite in Alzheimer's disease: a simple hypothesis that could be tested more thoroughly. Medical Hypothesis 48(5): 375-380.

9. Reed TT, Pierce WM, Turner DM, Markesbery WR, Butterfield DA (2009) Proteomic identification of nitrated brain proteins in early Alzheimer's disease inferior parietal lobule. J Cell Mol Med 13(8b): 2019-2029.

10. Grieb P (2016) Intracerebroventricular Streptozotocin Injections as a Model of Alzheimer's Disease: in Search of a Relevant Mechanism. Molec Neurobiol 53(3): 1741-1752.

11. Kamat PK (2015) Streptozotocin induced Alzheimer's disease like changes and the underlying neural degeneration and regeneration mechanism. Neural Regeneration Res 10(7): 1050-1052.

12. de la Monte SM, Wands JR (2008) Alzheimer's disease is type 3 diabetes-evidence reviewed. J Diabetes Sci Technol 2(6): 1101-1113.

13. Rosick ER (2006) The Deadly Connection Between Diabetes and Alzheimer's Life Extension Magazine, USA.

14. Brown RK, Nicolaas IB,Wong KK, Satoshi M, Frey KA (2014) Brain PET in Suspected Demen-tia: Patterns of Altered FDG MetabolismRadio Graphics 34: 684-701.

15. Van Dyke,K (2017) sent for publication Luminescence 2017, Netherlands. 


\section{Your next submission with Juniper Publishers} will reach you the below assets

- Quality Editorial service

- Swift Peer Review

- Reprints availability

- E-prints Service

- Manuscript Podcast for convenient understanding

- Global attainment for your research

- Manuscript accessibility in different formats

( Pdf, E-pub, Full Text, Audio)

- Unceasing customer service

Track the below URL for one-step submission https://juniperpublishers.com/online-submission.php 